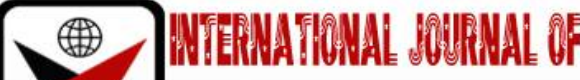

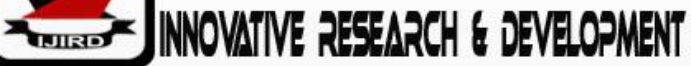

ISSN 2278-0211 (Online)

\section{Emotional Intelligence, Academic Self Concept, and Study Habit as Predictors of Academic Performance in Test and Measurement: Among Undergraduates of Ignatius Ajuru University of Education, Port Harcourt, Nigeria}

\begin{tabular}{c} 
Dorothy Chikaodi \\
\hline Senior Lecturer, Department of Educational Psychology, Guidance and Counselling, \\
Ignatius Ajuru University of Education, Port Harcourt, Nigeria \\
Dr. Inko-Tariah \\
Senior Lecturer, Department of Educational Psychology, Guidance and Counselling, \\
Ignatius Ajuru University of Education, Port Harcourt, Nigeria
\end{tabular}

\begin{abstract}
:
The paper examined emotional intelligence, academic-self concept and study habit as predictors of academic performance in Test and Measurement. A descriptive survey design was adopted while four research questions and their corresponding hypotheses guided the study. A sample of 213 was drawn from a population of 3,120 three hundred level students in the school. Data were collected using three self-structured instruments; an Emotional Intelligence Scale, Academic Self Concept Scale, and a Study Habit Inventory, Test and measurement examination scores were used to indicate academic performance. Research questions one to three were answered using simple linear regression, research question four was answered with multiple regression while ANOVA associated with regression was used to analyze the hypotheses at 0.05 level of significance. Results showed emotional intelligence, academic self-concept and study habit all predicted academic performance in Test and Measurement. It was also seen that the three factors jointly made $13.6 \%$ influence on performance in the course and it was recommended among others that students should be encouraged to develop these factors as they have strong influence on academic performance.
\end{abstract}

Keywords: Emotional intelligence, Academic self-concept, study habit, Test and measurement

\section{Introduction}

Every trainee teacher is required to take a course in Test and Measurement at a point in time to prepare for an integral part of teaching and learning which is evaluation of learning outcomes. A teacher with good content mastery, methodology, teaching aids, classroom management, etc. but without proper knowledge of assessing what students have learnt or will be able to learn can destroy all the good works he has done. Knowledge of test construction procedures which is a topic in Test and Measurement becomes necessary for a teacher to effectively perform his duties in the classroom. Test and Measurement as a course has both the theoretical and statistical parts making most students shy away from it. A lot of students in Arts and Social science feel harassed by this course as many have declared "they ran to Arts and Social Sciences to avoid calculations only to meet Test and Measurement as a compulsory course". High performance in this course becomes highly demanded that some students resort to various means of examination malpractice to pass this course warranting a look into predictors of academic performance in the course. Though there are various predictors of academic performance, the predictors considered in this study include emotional intelligence, academic self-concept and study habit.

Emotional intelligence (EI) as a concept was made popular by Daniel Goleman in his book "Emotional Intelligence: Why it can matter more than IQ" published in 1995. In this book, he was of the opinion that emotional intelligence is needed as much as intelligence quotient (IQ) for one to excel in all aspects of life including academics. Emotional intelligence as Kose (2013) noted refers to the ability of one to have awareness of, control and express one's emotions and handle interpersonal relationships judiciously and empathically i.e. being able to manage one's own emotions and that of others. It simply can be defined as the ability to understand one's emotional dispositions and that of others around you and harnessing these for the benefit of an organization or group i.e. bringing out the very best in others Mork (2019) in his write up listed the components of EI to include.

- $\quad$ Self-awareness refers to having knowledge of and being able to adjudge your own emotions and those of others. This includes the ability to recognize your emotions correctly and being aware that how one feels relates to what we do and that one's emotion has an effect on others. 
- Self-regulation: This as Mork noted refers to being able to redirect one's negative emotions into positive activities. Not being rigid, muddle through innovations, resolve conflicts.

- Social skills: This includes climate in a group. Effective and productive interaction with others which involves skills like paying attention, verbal communication skills, non-verbal communication skills, directorship skills and originating special bond with people.

- $\quad$ Self-motivation: Being intrinsically pushed for achievement, the person that is self- motivated according to Mork (2019) will expectedly have high qualities, be positive and have a natural drive for accomplishments.

- Empathy: The ability to comprehend how others feel by putting oneself in the position of others. This helps one to respond appropriately to the emotional disposition of others, which helps one to understand power kinetics.

Faltas in Heather (2019) noted the three models of EI namely Goleman's emotional intelligence model, Baron's emotional intelligence competencies model and Mayer, Salovey and Caruso's ability model.

Emotional intelligence in this study is anchored on the Baron's EI Competencies model, which is an arrangement of interrelated conducts that stem from emotional and social abilities that impact on performance and behavior. This model has five scales: self-perception, interpersonal, self-expression, stress management and decision making with 15 subscales of self-actualization, independence, interpersonal relationship, self-regard, emotional self-awareness, empathy, problemsolving, assertiveness, independence, emotional expression, social responsibility, flexibility and optimism. These proficiencies according to him drive behaviors and relationships of humans. These competencies are necessary for success in any aspect of life and more in academics where interaction with classmates, teachers, parents and significant others is important for effective academic work.

Academic self-concept refers to the way a student sees himself academically. Ordaz-Villegas and Reyes- Lagunes (2014) noted it as a student's perception of his academic prowess, which has a great impact on cognitive functioning. It is how one perceives his self-efficiency in academic subjects. A student that sees himself as not able to do well in a particular course may not even boarder to put in any effort due to a high expectancy for failure. Most students see Mathematical courses as beyond them and may not even attend the classes as they see it as a waste of time. This self-defeating attitude tags the student a failure even before examinations. Academic self- concept is derived from general self-concept which is how one sees himself. It is divided into two (a) Academic self-concept which can be a mathematical concept or literacy selfconcept. (b) Social concept made up of peer-related self-concept and teacher-related self-concept. Academic self-concept in this study is based on Dweck's Maremental theory which is one of the self- theories propounded by Dweck and two others. The self-theories as learning theory describes two types of students and the dispositions, they bring to learning situations which are;

The Entity theory which believes intelligence and abilities are fixed and cannot be improved on.

The student in this group believes in the innate abilities for performance, which is fixed and he, therefore, cannot perform beyond this fixed ability. The incremental theory on the other hand as Dweck (2019) stated believes that intelligence and ability are plastic attributes that can be improved on with persistence and hard work. Dweck believed that the students in this group affirm the possibility of acquiring knowledge through hard work even when the basic intelligence is not there. This study agrees more with the incremental theory as observation has shown that when students decide to put in time in their studies, they do well. There have been instances of students with low grades deciding to work harder and their grades improved tremendously. Dweck's 30 year's empirical research also supports this theory.

Study Habits are ways learners go about the business of learning. The habits the learner employs when studying involve copying and making of notes, drawing up effective personal time table, getting ready for examination, teacher consultation, etc. Having a good and healthy study habit is important in academic performance. Becton (2019) listed some of the study habits of highly effective students to include:

- $\quad$ Spacing work into short-time studies instead of long sessions without breaks.

- Having an effective and workable personal timetable and sticking to it.

- A regular studying pattern.

- $\quad$ Setting goals for the study.

- Prioritizing activities.

- $\quad$ Starting to study the most difficult things.

- Avoiding distractions while studying.

- Having effective and functional study groups.

- Using weekends to go through what you did for the week.

These, as he noted, have been seen to improve student's study habits and thereby academic success. Delaying studying till examinations are at the corner has never been the best as the law of reading says you must read something at least three times before it makes meaning.

The study habit concept for this study is anchored on Edema's (2019)'s modification of Gartner's Maturity Model for student's study habits. Gartner's maturity model is more appropriate for business and has six levels of maturity, level of survival, level of awareness, committed, proactive, service-aligned and partnership. The model describes the coming to age of an organization and how it progresses over the years using this model. Edema (2019) created a four-level model for students' study habits from Gartner's work. Each level having four qualities on examination, assignment, team projects and stress level experienced by the students.

The four levels he created include:

- Negligence: This represents a student who is never ready and therefore performs poorly in academics. This student does not attend lectures, does not take note of when assignments are due, does not participate in in-class 
activities and usually does not relate well with classmates. This, in other words, can be termed a non-academic student who is usually not focused and may drop out of school. This student does not have any study habits, as he does not believe he has come to school to study.

- Survival: A student at this level does the barest minimum. He puts in little or no effort in his studies and encounters problems with his teachers and classmates. He too is not focused and has poor study habits. This student has a tendency to also drop out or finish with very poor grades.

- Committed: This student is focused and knows why he is in school; he attends classes and enjoys doing school work. He has a healthy study habit, can work independently and also in a group. He does well academically and enjoys a high level of academic success.

- $\quad$ Proactive: The student at his level goes beyond classroom work and performs excellently in his examination. He has a very good study habit, starts studying well before an examination, possesses good leadership skills in group projects and always willing to do more. He prides himself on his academic prowess and stands out in any academic crowd.

- The researcher decided on this model as it adequately describes the study habits of students and the level of academic maturity they attain.

Academic performance is a measure of educational goals taken through tests, portfolios, etc. It measures what students have learned or gained after being exposed to a course of instruction. Bell (2018) defined academic performance as how well learners are able to meet laid down governmental and institutional excellence. Williams (2018) however noted that there are several factors that stipulate academic performance and not necessarily test grades. Some students she noted may not be the best graduating students in their desired classes but possess leadership qualities or score high in some standardized tests causing employers of labor and facilities to consider these criteria in selection. In support of these, Bell asserted that education and academic performance may not be the only route to favorable outcomes. Parents and guardians are interested in the performances of the children and wards more so in a developing country like Nigeria where paper qualification is celebrated above competencies. Children that get high grades see that they can easily get what they want from their parents as it is a thing of pride for parents. Success in any endeavor in life does not come cheaply or by coincidence, it is out of hard work and being focused on what is important at any point in time. Academic success comes from hard work and denning self some luxuries for the meantime to reap the success later on. This tends more to the theory of self-regulation which advocates for denial of immediate gratification to attain better success in the future. For the purpose of this study academic performance refers to test scores in the course Test and Measurement.

There are studies on factors predicting the academic performance of students. Some of these factors have been taken singly or in combination, others in various subjects but to the best of the researcher's knowledge, none has been to predict academic performance in Test and Measurement. In a doctoral thesis on the relationship between emotional intelligence and academic achievement in elementary school children by Futum in 2008, Six Seconds Emotional Intelligence Assessment for Youths (SEI-yr) and California Standardized Testing and Reporting Program (STAR) and achievement tests in English Language, Arts and Mathematics as a science were used for collection. Seventy students from two elementary schools were involved in the study. Results revealed that students diagnosed as learning disabled scored one standard deviation below their peers. It was also found that pupils with high Emotional Intelligence scored higher than those with low Emotional Intelligence. In another study on the Role of Emotional Intelligence for Academic Achievement for students, Preeti (2013) expressed the need for students to develop EI to be able to compete favorably with their peers. The study investigated factors that affected the growth of EI and the role it plays in the academic achievement of students. The work analyzed secondary data and found a positive relationship between Emotional Intelligence and academic achievement. It was noted that the teaching of emotional and social skills at school not only has positive effects on academic achievement during school but also long after school. Developing these skills gives one an edge in every aspect of life and helping students to develop this is thus very important. It was stressed that academic achievement without emotional intelligence does not equate to future success and not having emotional intelligence equates to weak personality and not being able to relate and work with others. In 2014, Kolachina did a study on the "impact of Emotional Intelligence on Academic Achievement of Expatriate College Students in Dubai. Students in higher educational institutions took part in this study and it was found that their emotional intelligence correlates positively with academic achievement and also that high and low achieving motivation students differed from each other on emotional intelligence, Another study was carried out by Hakimi and Bashiar (2014) on Emotional Intelligence, Self-Concept and Academic Performance of Senior Secondary School Student in Sokoto Metropolis of Sokoto state, Nigeria. Three hundred and fifty students were involved in the study. Data was collected using the adapted version of the Emotional Intelligence Quotient Scale by Akinboye's, Adolescent Personal data Inventory Subscale in Self Concept and test results in English and Mathematics. Results showed a significant relationship between emotional intelligence and academic performance. It was also found that the relationship between the emotional intelligence of male and female students differed significantly but no significant difference was found in the self-concept of male and female students. In 2018, a study on Emotional Intelligence as a predictor of Academic Performance Among Secondary School Students in Makurdi metropolis of Benue State involved 375 senior secondary II students and was carried out by Amalu. Emotional Intelligence scale was used for data collection and an achievement test in Mathematics was used as a measure of academic performance and data was analyzed using multiple regression analysis and it was found that a positive relationship exists between emotional intelligence and academic performance of students. Malik and Shahid (2016) studied the effects of EI on Academic Performance of Business Students in Pakistan, findings revealed EI to correlate weakly with academic performance. They, however, cited the work of Occonor which found emotional intelligence to strongly indicate the academic achievement of students. The result explains more the role emotional intelligence plays on what happens in the classroom, that students 
with high emotional intelligence will have better interactions with both classmates and teachers than the ones with low emotional intelligence

A study on the relationship between Academic Self Concept and Students' Academic Performance by Rady, Kabear and El-Nady (2016) revealed how students' academic self-concept relates to their academic performance. The study engaged 182 school-age children and their teachers in Freedom School for Basic Education in Cairo. It was found that a significant relationship exists between academic self-concept and academic performance of students. They found a gap between boys and girls on how they develop self-concept and factors that influence the development of academic selfconcept to include mental and physical growth, early educators and parenting style.

On study habits and academic performance of students, Rabia et al (2017) worked on study habits and academic performance of students. They investigated the relationship between study habits and academic performance of 270 students sampled from two colleges; the Government Allama Igbal College for women and Government Technical College for boys in Sialker. Results revealed a significant relationship between study habits and academic performance of students. In a related study by Maxwell and Eremie (2017) titled Study Habits of Senior Secondary School Students and Academic Performance in Rivers state, the study sampled 1500 students from four co-education schools randomly and used the General Study Habit Scale (GSHS) for data collection. Results revealed that differences exist in the responses of male and female students on interaction level, students' time management, class attitude, motivational level, and note-taking behavior.

Oluwatimilehin and Owoyele (2012) however investigated the relationship between study habits and students' academic achievement in core subjects at the Junior Secondary School Level in Ondo State of Nigeria, aspects of study habits like homework and assignment, time allocation for study, reading and note-taking, study period were checked and results show:

1. A low positive relationship between the sub-scales of study habits and academic performance of students.

2. The relationship between performance in Mathematics and the sub-scales of academic performance to be low.

3. Also, the relationship between performance in science and sub-scales of academic performance to be low.

They concluded that the results could be due to lack of interest or motivation as it is expected that studiousness should correlate positively and highly with academic performance.

\section{Method}

The study adopted a correlational design and a sample of 213 was drawn purposively from 3120 three hundred level students that took Test and Measurement as a compulsory course in the 2017/2018 academic session. Data was collected using four instruments, an emotional intelligence scale, an Academic Self Concept Inventory, a Study Habit Inventory and scores from Test and Measurement examination. The scales and test items on Test and Measurement were validated and reliability indices established that ranged from $0.64,0.69,0.71$ and 0.68 respectively. The instruments were given to the students and their results on the Test and Measurement examination obtained. Simple regression analysis and its associated ANOVA were used for research questions and hypotheses one to three while multiple regression and the associated ANOVA were used for research question and hypotheses four. All the analysis was at 0.05 level of significance.

\section{Results}

The results are presented based on the research questions and hypothesis

\subsection{Research Question One}

Does emotional intelligence predict academic performance of students in Test and Measurement?

\subsection{Hypothesis One}

Emotional intelligence does not significantly predict the academic performance of students in Test and Measurement.

\begin{tabular}{|c|c|c|c|c|c|c|}
\hline \multirow[t]{2}{*}{ Model } & $\mathbf{R}$ & \multicolumn{2}{|l|}{$\mathbf{R}^{2}$} & \multicolumn{2}{|l|}{ Adj $R^{2}$} & Std. Error of Estimates \\
\hline & 0.312 & \multicolumn{2}{|l|}{0.097} & \multicolumn{2}{|l|}{0.093} & 5.505 \\
\hline \multicolumn{7}{|c|}{ Analysis of Variance (ANOVA) } \\
\hline \multicolumn{2}{|c|}{ Model } & $\begin{array}{c}\text { Sum of } \\
\text { Squares }\end{array}$ & df & $\begin{array}{c}\text { Mean } \\
\text { Square }\end{array}$ & $\mathbf{F}$ & Sig \\
\hline \multicolumn{2}{|c|}{ Regression } & 689.388 & 1 & 689.388 & \multirow[t]{3}{*}{22.746} & \multirow[t]{3}{*}{0.000} \\
\hline \multicolumn{2}{|c|}{ Residual } & 6395.044 & 211 & \multirow[t]{2}{*}{30.308} & & \\
\hline \multicolumn{2}{|c|}{ Total } & 7084.432 & 212 & & & \\
\hline
\end{tabular}

Table 1: Linear Regression and ANOVA Analysis of Emotional Intelligence and Academic Performance

Analysis of research question one showed that when students' responses on emotional intelligence were regressed on their academic performance in Test and Measurement, an R-value of 0.313 was obtained, an $\mathrm{R}^{2}$ of 0.097 and an adjusted $\mathrm{R}^{2}$ of 0.093 were also gotten. From this result, it can be deduced that emotional intelligence independently accounted for $9.3 \%$ of the variation in students' academic performance in Test and measurement. Furthermore, an ANOVA analysis testing the significance of this value showed that an F-value of 22.746 was gotten at 1 and 211 degrees of freedom which yielded an associated p-value of 0.000 . Since the p-value obtained was lesser than 0.05 , it, therefore, indicates that emotional intelligence has a significant independent prediction on the academic performance of students in Test and 
Measurement. The null hypothesis was therefore rejected.

\subsection{Research Question Two}

Does academic self-concept predict academic performance of students in Test and Measurement?

\subsection{Hypothesis Two}

Academic self-concept does not significantly predict the academic performance of students in Test and Measurement.

\begin{tabular}{|c|c|c|c|c|c|c|}
\hline \multirow[t]{2}{*}{ Model } & $\mathbf{R}$ & \multicolumn{2}{|l|}{$\mathbf{R}^{2}$} & \multicolumn{2}{|l|}{ Adj $R^{2}$} & Std. Error of Estimates \\
\hline & 0.242 & 0.059 & & 0.054 & & 5.62 \\
\hline \multicolumn{7}{|c|}{ Analysis of Variance (ANOVA) } \\
\hline \multicolumn{2}{|c|}{ Model } & $\begin{array}{c}\text { Sum of } \\
\text { Squares }\end{array}$ & $\mathrm{df}$ & $\begin{array}{c}\text { Mean } \\
\text { Square }\end{array}$ & $\mathrm{F}$ & Sig \\
\hline \multicolumn{2}{|c|}{ Regression } & 416.149 & 1 & 416.149 & \multirow[t]{3}{*}{13.168} & \multirow[t]{3}{*}{0.000} \\
\hline \multicolumn{2}{|c|}{ Residual } & 6668.283 & 211 & \multirow[t]{2}{*}{31.603} & & \\
\hline \multicolumn{2}{|c|}{ Total } & 7084.432 & 212 & & & \\
\hline
\end{tabular}

Table 2: Linear Regression and ANOVA Analysis of Academic Self Concept and Academic Performance

In response to research question two, the table above showed that when students' response on academic selfconcept was used to predict their academic performance in Test and Measurement, an R-value of 0.242 was obtained, an $\mathrm{R}^{2}$ of 0.059 and adjusted $\mathrm{R}^{2}$ of 0.054 were also gotten. From this result, it can be deduced that academic self-concept independently accounted for $5.4 \%$ of the variation in students' academic performance in Test and measurement. Furthermore, an ANOVA analysis testing the significance of this value showed that an F-value of 13.16 was gotten at 1 and 211 degrees of freedom which yielded an associated p-value of 0.0005 . Since the $p$-value obtained was lesser than 0.05 , it, therefore, indicates that academic self-concept significantly predicted the academic performance of students in Test and Measurement. The null hypothesis was therefore rejected.

\subsection{Research Question Three}

Does study habit predict academic performance of students in Test and Measurement?

\subsection{Hypothesis Three}

Study habit does not significantly predict the academic performance of students in Test and Measurement.

\begin{tabular}{|c|c|c|c|c|c|c|}
\hline \multirow[t]{2}{*}{ Model } & $\mathbf{R}$ & \multicolumn{2}{|l|}{$\mathbf{R}^{2}$} & \multicolumn{2}{|l|}{ Adj R ${ }^{2}$} & Std. Error of Estimates \\
\hline & 0.240 & 0.060 & & 0.056 & & 5.617 \\
\hline \multicolumn{7}{|c|}{ Analysis of Variance (ANOVA) } \\
\hline \multicolumn{2}{|c|}{ Model } & $\begin{array}{l}\text { Sum of } \\
\text { Squares }\end{array}$ & $\mathrm{df}$ & $\begin{array}{c}\text { Mean } \\
\text { Square }\end{array}$ & $\mathrm{F}$ & Sig \\
\hline \multicolumn{2}{|c|}{ Regression } & 425.301 & 1 & 425.301 & \multirow[t]{3}{*}{13.476} & \multirow[t]{3}{*}{0.000} \\
\hline \multicolumn{2}{|c|}{ Residual } & 6659.131 & 211 & \multirow[t]{2}{*}{31.560} & & \\
\hline \multicolumn{2}{|c|}{ Total } & 7084.432 & 212 & & & \\
\hline
\end{tabular}

Table 3: Linear Regression and ANOVA Analysis of Study Habit and Academic Performance

Analysis of research question two showed that when students' responses on study habits were regressed on their academic performance in Test and Measurement, an R-value of 0.245 was obtained, an $\mathrm{R}^{2}$ of 0.060 and an adjusted $\mathrm{R}^{2}$ of 0.056 were also gotten. From this result, it can be deduced that study habits predicted about $5.6 \%$ of students' academic performance in Tests and measurement. Furthermore, an ANOVA analysis testing the significance of this value showed that an F-value of 13.476 was gotten at 1 and 212 degrees of freedom which yielded an associated p-value of 0.0005 . Since the p-value obtained was lesser than 0.05 , it, therefore, indicates that study habit has a significant independent prediction on the academic performance of students in Test and Measurement. The null hypothesis was therefore rejected.

\subsection{Research Question Four}

Do emotional intelligence, academic self-concept and study habit jointly predict the academic performance of students in Test and Measurement?

\subsection{Hypothesis Four}

Emotional intelligence, academic self-concept, and study habit do not significantly predict the academic performance of students in Test and Measurement. 


\begin{tabular}{|c|c|c|c|c|c|c|}
\hline \multirow[t]{2}{*}{ Model } & $\mathbf{R}$ & $\mathbf{R}^{2}$ & & \multicolumn{2}{|l|}{ Adj $\mathbf{R}^{2}$} & Std. Error of Estimates \\
\hline & 0.386 & 0.149 & & \multicolumn{2}{|l|}{0.136} & 5.372 \\
\hline \multicolumn{7}{|c|}{ Analysis of Variance (ANOVA) } \\
\hline \multicolumn{2}{|c|}{ Model } & $\begin{array}{c}\text { Sum of } \\
\text { Squares }\end{array}$ & $\mathrm{df}$ & $\begin{array}{c}\text { Mean } \\
\text { Square }\end{array}$ & $\mathrm{F}$ & Sig \\
\hline \multicolumn{2}{|c|}{ Regression } & 1053.026 & 3 & 351.009 & \multirow[t]{3}{*}{12.163} & \multirow[t]{3}{*}{0.000} \\
\hline \multicolumn{2}{|c|}{ Residual } & 6031.405 & 209 & \multirow[t]{2}{*}{28.858} & & \\
\hline \multicolumn{2}{|c|}{ Total } & 7084.432 & 212 & & & \\
\hline
\end{tabular}

Table 4: Multiple Regression and ANOVA Analysis of Emotional Intelligence, Academic Self Concept, Study Habit, and Academic Performance

According to the result displayed in table 4, a multiple regression coefficient of 0.386 was gotten from the joint contribution of emotional intelligence, academic self-concept, and study habit on the academic performance of students in Test and Measurement. From the same table, it was shown that an $\mathrm{R}^{2}$ of 0.149 was gotten, with a corresponding Adj $\mathrm{R}^{2}$ of 0.136. On the basis of the Adj $\mathrm{R}^{2}$, it, therefore implies that $13.6 \%$ of academic performance of students in Test and Measurement can be explained by the joint influence of emotional intelligence, academic self-concept and study habit. The remaining $86.4 \%$ can be attributed to other factors such as learning material, lecturers' competence, peer interaction etc. These values obtained were further subjected to ANOVA associated with multiple regression to test their significance. The result obtained showed an F-value of 12.163 at 3 and 209 degrees of freedom, with an associated p-value of 0.0005 , which was lesser than the chosen alpha of 0.05. This result, therefore suggests that emotional intelligence, study habit, and academic self-concept have a significant joint contribution to the academic performance of students. The null hypothesis was therefore rejected.

\section{Discussion}

Results on table 1 indicate an R-Value of 0.313 and adjusted R= Value of 0.097 and 0.093 were gotten which shows that emotional intelligence independently accounted for $9.3 \%$ of the variation in academic performance in Test and Measurement. On the hypothesis, the ANOVA revealed an F-value of $22.74 \%$ at 1 and 211 degrees of freedom with a PValue of 0.000 , which is less than the 0.05 level of significance. This shows that Emotional Intelligence has significant independent prediction on academic performance in Test and Measurement. This result upholds the findings of Preeti, Kolachina, Hakimi and Bashiar $(2013,2014 \alpha 2014)$ respectively who all found emotional intelligence to relate strongly with academic performance. The present result, however, disagrees with the findings of Malik and Shahid (2016) who found emotional intelligence to have only a weak relationship with academic performance. The result could be because emotional intelligence equips a student to be in touch with his emotions and that of others around him, which helps him interact more efficiently with others giving him an edge in adjusting to the school environment hence excelling in his academics.

The results in table 2 show an $\mathrm{R}^{2}$ of 0.054 meaning that academic self-concept independently accounted for $5.4 \%$ of the variation in students' academic performance in Test and Measurement. ANOVA analysis showing a p-value of 0.0005 as against the 0.05 level of significance indicates that academic self-concept significantly predicted academic performance in Test and Measurement. The result agrees with that of El- Nady (2016) who found academic self- concept to significantly relate to the academic performance of students and also a gap between boys and girls on how they develop self- concept. That academic self- concept positively predicted academic performance is not surprising as a student that sees himself as academically sound will work to prove himself so, while the one that believes he is not academically capable will believe that studying will be wasted effort. The development of a healthy academic self-concept should be encouraged among the students as this encourages the students to try to prove himself right in his academics.

On research question 3 and hypothesis 3, Table 3 shows, the linear regression analysis of study habits and academic performance of students revealed an adjusted $\mathrm{R}^{2}$ of 0.056 indicating that study habits predicted about $5.6 \%$ of students' academic performance in Test and Measurement. Results on ANOVA on the significance of this value showed a PValue of 0.000 to be less than 0.05 indicating that study habits significantly predicted academic performance in Test and Measurement. This result is in accordance with the findings of Rabia et al (2017) who found study habit to significantly relate to academic performance of students, the findings of Oluwatimilehin and Owoyele (2012) in their study of Relationship Between Study Habit and Students Academic Achievements in Core Subjects at the Junior Secondary School Level in Ondo State, however, disagrees with the present result. They found a low relationship between the sub-sets of study habits and academic performance of students in Mathematics and Science; they concluded that the result could be due to low students' interest and motivation. The present result anyway is expected as effective study habit results in good academic performance. Having a study timetable, proper note-taking, class participation, teacher consultation, turning in an assignment, relating well with other classmates in team assignments etc. should get a student ready for examinations and pass well in these examinations. A student who does not spend time on his studies does not expect to perform well in his academics.

Table 4 on Emotional Intelligence, Academic Self-Concept, and Study Habit jointly predicting academic performance of students in Test and Measurement, multiple regression analysis was done and an adjusted $\mathrm{R}^{2}$ of 0.136 was gotten indicating that $13.6 \%$ of academic performance of students in Test and measurement can be explained by the joint influence of emotional intelligence, academic self-concept and study habit of student while the remaining $86.4 \%$ can be accredited to numerous other factors that can influence academic performance. When put through ANOVA linked with multiple regression, a P-Value of 0.000 was obtained which is lesser than 0.05 thus implying that emotional intelligence, 
academic self-concept and study habit significantly contribute jointly to the academic performance of students. This agrees with the results of Preeti (2013), Kolachina (2014), Hakini and Bashiar (2014), El- Nady (2016) and Rabia (2017) who all found emotional intelligence, academic self-concept and study habit to individually relate positively with academic performance while the finding of Oluwatimilehin and Owoyele (2012) and Malik and Shahid (2016) disagreed with the present result. The result is expected since each factor independently predicted academic performance significantly.

\section{Summary}

The study investigated Emotional Intelligence, Academic Self Concept, and Study Habit as predictors of Academic Performance in Test and Measurement. Correlational design was adopted and 213 students participated. Data was analyzed using regression analysis and its associated ANOVA. It was found that the three factors both independently and jointly predicted academic performance in Test and Measurement.

\section{Conclusion}

The study investigated Emotional intelligence, Academic Self-concept and Study habit as predictors of students' academic performance in Test and Measurement. Data was collected through three questionnaires on Emotional Intelligence, Academic Self-concept and Study habits and final test scores on Test and measurement. Simple linear regression and ANOVA were used for analysis and from the findings. It was concluded that:

- Emotional Intelligence can independently predict the academic performance of students.

- Self-concept independently predicted the academic performance of students.

- Study habits also independently predicted the academic performance of the student.

- Jointly the three factors can explain $13.6 \%$ of the academic performance of students in Test and Measurement.

\section{Recommendations}

The following recommendation was made.

- Students are encouraged to develop emotional intelligence, as this is necessary for success in every aspect of life.

- Teachers, parents and significant others should help children right from the early stage to develop positive academic self-concept as this can independently predict success in academic endeavors.

- A healthy study habit is necessary if a student is to do well in school. Students should be helped to develop strong study habits.

- $\quad$ Parents are encouraged to help their children develop positive study habits by buying books for them instead of video games that they get addicted to and do not have time to read their books.

- Students at all levels should be given questionnaires on these factors to know what is accepted as positive emotional intelligence, academic self-concept and study habit

\section{References}

i. Amalu, M. N (2018). Emotional Intelligence as Predictor of Academic Performance Among Secondary School Students in Markurdi metropolis of Benue State. International Journal of Scientific Research in Education 11(1), 6370.

ii. Becton, L. (2019). 10 Habits of Highly Effective Students Education Corner. Retrieved from https:// www.education corners.com.

iii. Bell, J. B (2018). Define Academic Performance. The Classroom https://theclassroom.com

iv. Edema, R. (2019). Maturity Model Example/ Student Study Habit. Roli Edema.com. https://www.roliedema.com>mat

v. Eriguc, G. \& Kose, S. D. (2013). Evaluation of emotional intelligence and communication skills of health care manager candidates: A structural equation modelling. International Journal of Business and Social Science, 4 (13),114-123 https://www.researchgate.net

vi. Hakimi, M. W \& Basher, A. M (2014). Emotional Intelligence, Self-concept and Academic Performance of Senior Secondary School Students in Sokoto Metropolis. African Journal Online 33 (2) 35-48 https.www.ajol.info>article>view.

vii. Heather, C. (2019). The Theories of Emotional Intelligence Explained. Positive Psychology.com https://positive psychology.com/emotional intelligence theories.

viii. Kolachina, A. (2014). Impact of Emotional Intelligence on Academic Achievement of Expatriate College Students in Dubai. International Journal of Social Science and Humanities Research, 2(2) 97-103 www.researchpublish.com>f.

ix. Malik, S. Z \& Shahid, S. (2016). Effect of Emotional Intelligence on Academic Performance Among Business Students in Pakistan. Bulletin of Educational Research. 38(1). 197-208. Pu.edu.pk>ier>PDF.files

x. Maxwell, D. \& Eremie, M. D (2017). Study Habit of Senior Secondary School Students and Academic Performance in Rivers State. International Journal of Innovative Education Research. 5(3) 52-59.

xi. Mork, N. (2019, April 28). The 5 components of emotional intelligence for great leaders. Addicted 2 Success. https://addicted2success.com

xii. Oluwatimilehin, J. T $\alpha$ Owoyele, J. W (2012). Study Habit and Academic Achievement in Core Subjects and Junior Secondary School Students in Ondo State Nigeria. Bulgarian Journal of Science and Education Policy 6(1) 155-169.

xiii. Rabia, M, Mubarak, N; Tallat, H. $\alpha$ Nasiri, W (2017). A study on Study Habit and Academic Performance of Students. International Journal of Asian Social Science 7(10) 891-897. 
xiv. Rady, A. E. H; Kabeer, S $\alpha$ El-Nady, T. M (2016). Relationship between Academic Self-concept and Students Performance among School-Age Children. American Journal of Nursing Science, 5(6) 295-302.

xv. Williams, E. (2018). What is the Meaning of Academic Performance? Chron. https://work.chron.com>meaning.a... 